\title{
An Account on Functionalization of Materials: Influence on the Performance Evaluation of Solid State Devices ${ }^{\dagger}$
}

\author{
Madhumita Mukhopadhyay ${ }^{1, *}$, Jayanta Mukhopadhyay ${ }^{2, *}$, Abhijit Das Sharma ${ }^{2}$ \\ 1 Department of Chemistry, Amity Institute of Applied Sciences (AIAS), Amity University, Kolkata-700156, India; \\ mmukhopadhyay@kol.amity.edu (M.M.); \\ 2 Fuel Cell and Battery Division, CSIR-Central Glass and Ceramic Research Institute, Kolkata - 700 032, India; \\ jmukhopadhyay75@gmail.com (J.M.); adassharma1@gmail.com (A.D.S.); \\ * Correspondence: mmukhopadhyay@kol.amity.edu (M.M.),jmukhopadhyay75@gmail.com (J.M.); \\ $\dagger$ Presented at Materials Chemistry and Physics (Materials Chemistry 2020) - International e-Conference
}

Received: 16.09.2020; Revised: 20.09.2020; Accepted: 24.09.2020; Published: 27.09.2020

\begin{abstract}
The power sector is one of the major constituents of a country's infrastructure. In this context, solid-state devices based on fuel cells have gained significant interest owing to their variable fuel usage, better performance evaluation, and tailored long-term endurance. In such an aspect, the primary role is employed by the materials viz. electrode and electrolyte irrespective of the operating temperature.

An account will be provided by the speaker on the correlation among tailoring the properties of the electrode through functionalization during synthesis and performance evaluation of the solid-state devices. Research work on functional anode materials applicable to high temperature fuel cells will be discussed. Functionalization of Ni-yttria stabilized zirconia composite through particulate deposition technique enables the formation of unique $\mathrm{Ni@SZ}$ microstructure, thereby resulting in a high current density of $3.7 \mathrm{~A} . \mathrm{cm}^{-2}$ at $800^{\circ} \mathrm{C}$ for coupon cell $(\phi 16-32 \mathrm{~mm})$ with high endurance for $2000 \mathrm{hrs}$. Penetration depth analysis of such cermet has been carried out successfully as a function of Ni content. The effectivity of such anodes will also be discussed with multiple fuels. For low-temperature applications, polymer-based electrolytes are employed. Functional poly (ethylene oxide) based electrolyte with optimized compositions are reported to significantly enhance the performance with even better long term tenability.
\end{abstract}

Keywords: fuel cell; funcational material; core-shell; polymer electrolyte; performance evaluation.

(C) 2020 by the authors. This article is an open-access article distributed under the terms and conditions of the Creative Commons Attribution (CC BY) license (https://creativecommons.org/licenses/by/4.0/).

\section{Funding}

This research received funding from CSIR and Amity University, Kolkata, India.

\section{Acknowledgments}

MM acknowledges Amity University, Kolkata, for financial and infrastructural support to carry out this work. ADS and JM intend to acknowledge Director, CSIR-CGCRI, for his kind permission to present the research work.

\section{Conflicts of Interest}

The authors declare no conflict of interest. 